\title{
Mouse Models of Radiosensitivity
}

\section{Eugenia M Yazlovitskaya ${ }^{1,2 *}$}

${ }^{1}$ Department of Medicine, Division of Nephrology, Vanderbilt University Medical Center, USA

${ }^{2}$ Vanderbilt-Ingram Cancer Center, Vanderbilt University, Nashville, TN, USA

Ionizing radiation (IR) is a known environmental, medical, and military hazard that can produce dreadful health impairments. At the molecular and cellular level, radiation toxicity paradigm defines DNA damage as the most critical biological effect inferred by IR $[1,2]$. Specifically, IR produces clustered DNA damage, particularly doublestrand DNA breaks (DSBs). Signal transduction pathways and DNA repair systems are activated in response to IR to protectcells from injury. Discovery of radiosensitive human diseases has revealed two disease classes consistent with the distinct biological responses to IR: recognition of DSBs and repair of DSBs.

After tumor irradiation, the patients with one class of radiosensitive diseases developed severe dermatitis and deep tissue necrosis. This disease class includes ataxia-telangiectasia (AT) [3], the Nijmegen breakage syndrome (NBS) [4], ataxia-telangiectasia-like disorder (ATLD) [5] and Nijmegen breakage syndrome-like disorder (NBSLD) [6]. Genes responsible for these disorders have been identified as ATM for AT, NBS1 for NBS, MRE11A for ATLD and RAD50 for NBSLD [7]. Proteins encoded by these genes are all required for checkpoint response, a signal transduction pathway that recognizes DSBs [8].

Another class of radiosensitive diseases exhibits severe combined immunodeficiency (SCID), and the responsible genes are DNA-PKcs, Artemis and LIG4 (DNA ligase IV) [9]. Proteins encoded by these genes are involved in the repair of DSBs viaa process called non-homologous end-joining (NHEJ) [10].

Identification of genes responsible for radiosensitive diseases allowed for development of radiosensitive mouse models. Mice deficient in Atm were created for targeting the checkpoint response [11]. However, inactivation of Mre11, Rad50, or Nbs1 led to early embryonic lethality, allowing only for models with conditional knockout of these genes. In addition to MRN complex (Mre11, Rad50 and Nbs1) which recognizes DSB end and recruits ATM, other proteins are essential for IR-induced checkpoint and cell cycle arrest including $\mathrm{H} 2 \mathrm{AX}$ and p53 [12]. Mice deficient in these proteins also demonstrate increased radiosensitivity [13]. SCID mouse models represent genes involved in IR-induced DSB repair through NHEJ [14].

Studies of mouse models of radiosensitive diseases demonstrated that immunodeficiency and elevated risk of leukemia/lymphoma associated with radiosensitivity is attributed to defects in DNA damage response and repair mechanisms acquired during development of the immune system. In the absence of checkpoint response, the risk of abnormal end joining of broken DNA is increased. Without NHEJ, the DSBs must be repaired by other less specific mechanisms to insure cell survival thus increasing probability of errors. Consequently, accumulation of cells with the abnormal DNA rearrangements may increase the risk of developing lymphoma/leukemia.

The most recent studies of molecular mechanisms underlying IRinduced cell death emphasize multiple pathways regulating cellular response to IR beyond DNA damage and repair. These pathways include membrane-dependent signaling pathways and by stander effect, a process of cellular response to irradiation of the neighboring cells rather than to direct IR exposure [15]. Targeting proteins regulating these pathways opens new avenues for development of new animal models of radiosensitivity. One recent example is a knockout of mitochondrial tumor suppressor Fus1 in mice. This model demonstrated novel radioprotective function for Fus1 whichmodulates radiosensitivity of normal tissues via regulation of anti-oxidant response pathways [16]. Interestingly, Fus1-deficient mice had increased frequency of spontaneous tumors and immunologic disorders [17,18], consistent with the mechanistic link of radiosensitivity to abnormal immune functions and increased risk of cancer.

\section{References}

1. Hutchinson $F$ (1966) The molecular basis for radiation effects on cells. Cancer Res 26: 2045-2052.

2. Blok J, Loman H (1973) The effects of gamma-radiation in DNA. Curr Top Radia Res Q 9: 165-245.

3. Taylor AM, Harnden DG, Arlett CF, Harcourt SA, Lehmann AR, et al. (1975) Ataxia telangiectasia: a human mutation with abnormal radiation sensitivity. Nature 258: 427-429.

4. Taalman RD, Jaspers NG, Scheres JM, de Wit J, Hustinx TW (1983) Hypersensitivity to ionizing radiation, in vitro, in a new chromosomal breakage disorder, the Nijmegen Breakage Syndrome. Mutat Res 112: 23-32.

5. Fiorilli M, Antonelli A, Russo G, Crescenzi M, Carbonari M, et al. (1985) Variant of ataxia-telangiectasia with low-level radiosensitivity. Hum Genet 70: 274-277.

6. Waltes R, Kalb R, Gatei M, Kijas AW, Stumm M, et al. (2009) Human RAD50 deficiency in a Nijmegen breakage syndrome-like disorder. Am J Hum Genet 84: 605-616.

7. Carney JP, Maser RS, Olivares H, Davis EM, Le Beau M, et al. (1998) The hMre11/hRad50 protein complex and Nijmegen breakage syndrome: linkage of double-strand break repair to the cellular DNA damage response. Cell 93:477486 .

8. Williams RS, Williams JS, Tainer JA (2007) Mre11-Rad50-Nbs1 is a keystone complex connecting DNA repair machinery, double-strand break signaling, and the chromatin template. Biochem Cell Biol 85: 509-520.

9. van der Burg M, ljspeert $\mathrm{H}$, Verkaik NS, Turul T, Wiegant WW, et al. (2009) A DNA-PKCs mutation in a radiosensitive T-B- SCID patient inhibits Artemis activation and nonhomologous end-joining. J Clin Invest 119: 91-98.

10. Wang C, Lees-Miller SP (2013) Detection and repair of ionizing radiationinduced DNA double strand breaks: new developments in nonhomologous end joining. Int J Radiat Oncol Biol Phys 86: 440-449.

11. Barlow C, Hirotsune S, Paylor R, Liyanage M, Eckhaus M, et al. (1996) Atmdeficient mice: a paradigm of ataxia telangiectasia. Cell 86: 159-171.

12. Masuda Y, Kamiya K (2012) Molecular nature of radiation injury and DNA repair

*Corresponding author: Eugenia M Yazlovitskaya, Department of Medicine Division of Nephrology, Vanderbilt University Medical Center, Nashville, TN 37232, USA, Tel: 1-615-322-6679; Fax: 1-615-343-7156; E-mail: eugenia yazlovitskaya@vanderbilt.edu

Received July 22, 2013; Accepted July 24, 2013; Published July 31, 2013

Citation: Yazlovitskaya EM (2013) Mouse Models of Radiosensitivity. J Bioequiv Availab 5: e36. doi:10.4172/jbb.10000e36

Copyright: (C) 2013 Yazlovitskaya EM. This is an open-access article distributed under the terms of the Creative Commons Attribution License, which permits unrestricted use, distribution, and reproduction in any medium, provided the original author and source are credited. 
disorders associated with radiosensitivity. Int J Hematol 95: 239-245.

13. Bassing $\mathrm{CH}$, Alt FW (2004) H2AX may function as an anchor to hold broken chromosomal DNA ends in close proximity. Cell Cycle 3: 149-153.

14. Weaver DT (1995) What to do at an end: DNA double-strand-break repair. Trends Genet 11: 388-392.

15. Prise KM, Schettino G, Folkard M, Held KD (2005) New insights on cell death from radiation exposure. Lancet Oncol 6: 520-528.

16. Yazlovitskaya EM, Uzhachenko R, Voziyan PA, Yarbrough WG, Ivanova AV
(2013) A novel radioprotective function for the mitochondrial tumor suppressor protein Fus1. Cell Death Dis 4: e687.

17. Ivanova AV, Ivanov SV, Pascal V, Lumsden JM, Ward JM, et al. (2007) Autoimmunity, spontaneous tumourigenesis, and IL-15 insufficiency in mice with a targeted disruption of the tumour suppressor gene Fus1. J Pathol 211 : 591-601.

18. Ivanova AV, Ivanov SV, Prudkin L, Nonaka D, Liu Z, et al. (2009) Mechanisms of FUS1/TUSC2 deficiency in mesothelioma and its tumorigenic transcriptional effects. Mol Cancer 8: 91. 